\title{
Smart Agents: When Lower Search Costs for Quality Information Increase Price Sensitivity
}

\author{
KRISTIN DIEHL \\ LAURA J. KORNISH \\ JOHN G. LYNCH, JR.*
}

\begin{abstract}
Recent consumer research suggests that lowering search costs for quality information reduces consumer price sensitivity by creating greater perceived differentiation among brands (e.g., Kaul and Wittink 1995; Lynch and Ariely 2000). We argue that lowering quality search costs by smart agents can have the opposite effect on differentiation and price sensitivity. Smart agents screen through a universe of alternatives, recommending only a handful well-matched to the customer's quality preferences. In this research, we ask and answer the following questions: In markets in which price and quality are uncorrelated, will the use of screening agents increase or decrease prices paid compared to searching from an unordered list of options? Will increasing the size of the store's underlying assortment increase or decrease prices paid when options have been screened on quality? In markets where higher priced goods have higher quality, will the use of screening agents increase or decrease prices paid and quality selected? Experiments 1 and 2 test the effect of quality screening when price and quality are uncorrelated. We then present an analytic model for markets in which price and quality are correlated. We deduce that ordering can cause price and quality to increase or decrease depending on the slope of the price-quality relationship in comparison with the relative importance of price in the utility function. We find support for this model in experiment 3.
\end{abstract}

$\mathrm{P}$ opular press analysts and marketing scholars have predicted that lowered search costs through the internet should lead to intensified competition and greater price sensitivity (e.g., Anders 1998; Gove 1999; Kuttner 1998; Quelch and Klein 1996). Several scholars have recently countered with theories or empirical evidence distinguishing the effects of lower search costs for quality information from those of lowering search costs for other information about prices or locations of products. Alba et al. (1997) relied on the literature on the economic effects of advertising to argue

\footnotetext{
*Kristin Diehl (diehl@moore.sc.edu) is assistant professor of marketing, University of South Carolina, Columbia, SC 29208. Laura J. Kornish (kornish@duke.edu) is assistant professor and John G. Lynch, Jr. (john.lynch@duke.edu) is Hanes Corporation Foundation Professor of Business Administration at the Fuqua School of Business, Duke University, Box 90120, Durham, NC 27708-0120. This article is based on an essay in Kristin Diehl's dissertation, written at Duke University under the direction of the other two authors. The authors thank the reviewers, the associate editor and the editor, dissertation co-chair Jim Bettman, Gregory Besharov, Jonathan Levav, Rick Staelin, Pat West, and Gal Zauberman for helpful comments on previous drafts of the paper and thank colleagues at Duke University, Indiana University, and the University of California, Los Angeles, for comments on presentations of this research. They thank Carl Mela for help with analytical issues in the appendixes. This article is dedicated to the memory of Emily Lynch Gómez.
}

that the internet, like differentiating advertising, can lower the costs of search for differentiating quality information. The advertising literature shows that advertising price information increases price sensitivity but advertising quality information reduces the perceived substitutability of competing brands and thereby decreases price sensitivity (e.g., Boulding, Lee, and Staelin 1994; Kaul and Wittink 1995; Mitra and Lynch 1995). Differentiating advertising allows consumers with heterogeneous tastes to find brands that match their tastes (Rosen 1978); consumers might pay more but be better off than without differentiating advertising because they are able to find better fitting brands with lower effort (Ehrlich and Fisher 1982; Mitra and Lynch 1996).

In the context of electronic commerce, researchers have concluded that improved access to quality information will decrease price sensitivity (Bakos 1997; Degeratu, Rangaswamy, and Wu 2000; Lal and Sarvary 1999; Lynch and Ariely 2000). Consistent with the arguments of Alba et al. (1997), Lynch and Ariely found that lowering search costs for quality decreased consumer price sensitivity and contributed to greater liking for the chosen brands in a subsequent taste test. These findings are consistent with the advertising literature and also agree in spirit with the growing body of work showing that the internet is not creating 
highly price competitive markets or frictionless commerce (e.g., Brynjolfsson and Smith 2000).

\section{Lowering Quality Search Costs by Quality Screening Agents}

Overlooked in all work to date on this topic is the fact that there are different ways to lower search costs for quality; we will argue that these should have different effects on consumer price sensitivity. Alba et al. (1997) maintained that the most important benefit of on-line shopping to consumers is not greater selection, lower cost of search for price information, or deeper quality information. They pointed to electronic screening as the most important development in on-line shopping. When a screening agent has some approximation of the consumer's utility function, it can sort through thousands of options and narrow the field to those few that closely match that utility function. The consumer then expends search effort only to inspect and evaluate the recommended few but is able to select quality as good as if he or she had searched exhaustively through the entire inventory of an on-line store or mall. Screening lowers the search cost for quality information by saving the consumer the effort of directly inspecting quality information on products with low likelihood of being chosen. Contrast this with lowering cost of quality information per inspected item. For example, Lynch and Ariely (2000) operationalized low search costs for quality by greater depth of available wine review information and less need to drill down to discover that information in comparison with a high search cost condition.

The booming academic and commercial interest in personalization technology attests to the potential benefit of screening of quality information (e.g., Gershoff and West 1998; Häubl and Trifts 2000; Konstan et al. 1997; West et al. 1999). Alba et al. (1997) liken a screening agent to a supersalesperson with excellent knowledge of both the qualities of the inventory and the tastes of the buyer. Without such screening, they assert, there is little benefit to the consumer of having access to a dramatically increased pool of options on the internet. It matters little whether the underlying assortment has 100 or 100,000 alternatives if consumers would stop searching long before the larger inventory would come into play. (We focus on choice from among imperfect substitutes and ignore the case in which the consumer seeks a specific item such as a book title.)

To date, there have been no published studies of how electronic screening affects consumer price sensitivity. Intuitively, the effects of such screening should be similar to other means of making quality information more abundant or easy to process. In general, empirical research suggests that anything that makes an important attribute easier to process will increase its weight in decision making. See, for example, Russo's (1977) work on unit price information or Slovic and McPhillamy's (1974) finding that making alternatives comparable on one attribute and not others increases the weight of the common attribute. By compressing mul- tiple attributes into a single dimension captured by ordinal position on a list, quality information becomes more transparent. Häubl and Murray (2003) find the inclusion of an attribute in an electronic recommendation agent renders this attribute more prominent in consumers' purchase decisions.

Despite the intuitive plausibility of the notion that screening on quality should decrease consumer price sensitivity and increase prices paid, we will argue that the opposite is often true. A good quality-screening agent causes the consumer's consideration set to have closer substitutes compared to a random list generated from the same assortment. With an ordered list from a screening agent, there will be many good choices with nearly comparable quality, so price is more likely to play a deciding role. A similar argument can be made that larger assortments, when ordered, provide consumers with closer substitutes (compared to an ordered list from a smaller assortment). Consumers benefit from larger retailer assortments in the presence of screening; they are able to find lower prices and better quality (cf. Alba et al. 1997).

\section{Ordered and Random Search}

In the research we report below, we contrast "ordered" search tools that create a strong correlation between expected quality and position in a list with "random" search tools that create no such correlation. Smart agents can create helpful orderings by using information about a searcher's preferences and enable an ordered search. In contrast, a list of options drawn randomly from the assortment and listed in no particular order would lead to a random search.

Many Web search engines create orderings based on alphabetic listing or simple keyword match; these produce weak correlations, yielding little or no reduction in search cost for quality information. However, specialized screening tools have been created for a variety of product categories such as wireless phones, pets, and movies. These tools elicit preferences from the user and then list options in an order that is highly correlated with the user's preference structure.

How should the use of ordered or random tools affect consumer search behavior? Prior research on sequential search has different models of ordered and random search, depending on whether the alternatives are a priori differentiated or undifferentiated. In both types of models, consumers are assumed to encounter options sequentially and stop searching when expected cost of searching one more item exceeds the expected benefit. Random search models assume each alternative searched arises from some random draw from the underlying population; the consumer has equal priors on all alternatives (e.g., Kohn and Shavell 1974; Moorthy, Ratchford, and Talukdar 1997). This corresponds to a zero rank order correlation between list position and expected utility. Ordered search models assume that, for each alternative, searchers have a different prior or predicted level of quality, $\hat{Q}$, that is imperfectly related to true quality, $Q$. The most promising options are explored first. Searchers consider alternatives in order of their $\hat{Q}$ values (Hauser and 
Wernerfelt 1990; Roberts and Lattin 1991; cf. Weitzman 1979).

\section{Ordered Search Tools Improve Both Price and Quality}

In experiment 1, we consider effects of a search tool that orders on quality net (minus) price. In experiment 2, we examine effects of ordering on quality alone. Here, it is not surprising that buyers choose higher quality items. However, we assert (hypothesis 1) that when price and quality are uncorrelated, sorting helps the buyer do better on both dimensions - to choose a higher quality item at a lower price. (Experiment 3 examines what happens given positive pricequality correlation.)

H1: When products are ordered by expected quality or expected quality net price, consumers will pay lower prices in ordered than in random search.

There are two reasons for hypothesis 1 . First, the top items in the sorted list are better prospects in overall value compared to random draws. Second, the top items in the sorted list are closer quality substitutes compared to random draws. Sorting on one attribute (e.g., quality) produces a set of top alternatives that are homogeneous on the sorted attribute but heterogeneous on unsorted attributes (e.g., price). It therefore becomes more likely that a nonsorted variable will be the deciding factor in choice, compared to when alternatives are not sorted. We explain these reasons further below and augment the argument that ordering leads to lower prices paid with an analytic derivation found in appendix A.

Ordering Leads to Oversampling Good Parts of the Distribution. First, with ordering, the subject sees alternatives drawn from a particular end or corner of the distribution. (We use the phrase "end of the distribution" to refer to an extreme part of a marginal or one-dimensional distribution; likewise, a "corner of a distribution" refers to an extreme part of a joint distribution.) The ordered condition creates an oversampling in that part of the distribution compared to the random condition; that is, the draws in that part of the distribution are sparser in the random condition. With a dense grouping of draws, there are more chances to find one that has very favorable values on both dimensions, price and quality. This first reason does not require the ordering to be perfect (i.e., completely reflecting the consumer's own assessments of utility), but it does require that the ordering be helpful, in that alternatives higher in the list have, on average, higher utility. ${ }^{1}$ The sorted list allows the consumer to be choosier in the sense of having a higher reservation value, which dictates when to stop searching and to purchase.

\footnotetext{
${ }^{1}$ One example of an "unhelpful" ordering would be a listing of the items in ascending quality. Another, less obviously unhelpful listing would be one that sorted on ascending price, but for an item in which there is a very strong positive quality-price relationship. By looking at the lowest priced items, you are also looking at very low quality items, so the expected net value is not higher for the top items in the list.
}

Ordering Induces Greater Substitutability of Top Options. Second, for many familiar distributions, the top choices from a sorted list are closer substitutes compared to a random sample of the same size. The close competition between alternatives increases the chance that the nonsorted variable can be the deciding factor in the selection. The closeness gives some diagnostic power to the other variable (e.g., price when the sort is on quality) and improves the expected level of that other variable in the chosen alternative. If the consumer truly cares about $Q-P$, this second effect is relevant when the sort is on $\hat{Q}$ alone, $P$ (Price) alone, or $\hat{Q}-P$.

To understand why good ordering by an agent causes greater substitutability of top considered options, first consider the properties of the best, second best, third best, and so on, from a random sample of size $n$ from a randomly ordered list. Order statistics give the expected values of the $i$ th best draws of a random sample of size $n$ from some parent distribution (e.g., David 1981). If quality is uniformly distributed over an interval from zero to one, the expected values of the best, second best, third best, and so on, of $n$ alternatives are $n /(n+1),(n-1) /(n+1),(n-2) /(n+1)$, and so on. The expected value of the advantage of the best over second best is $1 /(n+1)$. Larger sample sizes imply closer competition between best and second best options.

Suppose that a consumer is shopping for an electronic birthday card at a store with $N=250$ cards in the assortment. Assume that the store's assortment is itself some random sample from a uniform distribution and that the consumer samples $n \ll N$ cards in a random search. Assume that the consumer samples and considers $n=9$ cards. The expected value of the best card considered will be at the ninetieth percentile and that of the second best will be at the eightieth percentile. If she sampled only four cards, the best would be at the eightieth and the second best at the sixtieth percentile.

If, however, she is searching from an ordered list, the effective sample size is $N$, not $n$, because the search agent considers all $N$ alternatives to produce the order. As long as the consumer starts with the first-ranked card and examines two or more cards, the best alternative considered will be at the $(N /[N+1]=)$ 99.6th percentile, the second best at the $([N-1] /[N+1]=) 99.2 \mathrm{~d}$ percentile, and the expected advantage of the best over the second best is $1 /(N+1)=0.4$ percentile points-a much smaller advantage than $1 /(n+1)$ when $n \ll N$.

A similar conclusion follows for the normal distribution. Although there is no closed form expression for the expected advantage of the best over the second best in this case, we can draw the same conclusion from tabled data (see Mosteller and Rourke 1973, app. A-16).

This greater substitutability of top options in ordered than in random search depends on the distribution of utilities of the cards being well behaved. In particular, distributions with very long, thin tails can produce counterexamples to the statistical assertion that the largest values from larger samples are closer together on average than the largest values 
from smaller samples. (Contact the authors for details.) We will test hypothesis 1 empirically in experiments in which consumers search for products that have a roughly normal distribution of utilities.

The size of the gap between the best and the second best alternatives in a set of considered alternatives determines the consumer's willingness to pay a premium for the best rather than the second best. The smaller sample sizes lead to bigger gaps. If the advantage of the best over the second best alternative is smaller in the ordered case than in the random, consumers will be willing to pay a smaller price premium in the ordered case than in the random.

The logic supporting hypothesis 1 holds when prices and quality are independent. Independence prevails in horizontally differentiated markets in which consumers have different definitions of quality based on personal fit. In experiments 1 and 2, price and quality were independent. We explore the implications of a positive price-quality correlation (as would be typical in vertically differentiated markets) in experiment 3.

\section{Effects of Assortment Size on Price and Quality in Ordered Search}

The logic that underlies hypothesis 1 also speaks to the effect of assortment size on price. Just as ordering leads to an oversampling in a part of the distribution compared to random draws, increasing the size of the assortment of cards increases the density of options in every part of the distribution. Therefore, the alternatives are more dense in the attractive end (or corner) of the distribution so we have both more options from which to select an outstanding option as well as closer competition (leading to diagnostic power for the nonsorted criterion) among the top options. Hypotheses 2 and 3 each compare the effects of ordering in large assortments and small assortments that have the same mean and variance of price and quality.

H2: Consumers will pay lower prices when choosing from large assortments than they will from small assortments when products are ordered (either by expected quality or expected quality net price).

H3: Consumers will choose higher quality products from large assortments than they will from small assortments when products are ordered (either by expected quality or expected quality net price).

Neither hypothesis 2 nor hypothesis 3 follows when products are ordered randomly. As long as the optimal behavior is to stop searching at some number of options $n \ll N$, the optimal stopping point is sensitive only to the underlying distribution, not the assortment size.

In experiment 1, we test these hypotheses empirically. Each subject searched for greeting cards for two specifically described recipients. For one of these, the cards were ordered by expected quality net price and, for the other, cards were in a random order. We varied whether the consumer was shopping from a large assortment of cards or from a small assortment of cards with the same mean and variance.

\section{EXPERIMENT 1: EFFECTS OF ORDERED VERSUS RANDOM AGENTS}

Experiment 1 compares ordered and random search to examine effects on prices paid (hypothesis 1) for electronic birthday cards. We varied assortment size (250 vs. 75 cards in underlying assortment) to test corollary hypotheses 2 and 3. The primary dependent variable was price paid for the chosen card. We also measured its quality and the extent of search before its selection.

\section{Method}

Stimulus Creation and Scoring of Card Quality. The stimuli for the research were 250 electronic birthday cards. We developed a multiattribute quality score for each card, $Q$, and regressed $Q$ values onto card characteristics to yield a predicted card quality, $\hat{Q}$, as follows.

First, we determined the relevant dimensions and scored the cards on the dimensions. We elicited a set of dimensions along which the cards differed from five volunteers, using a Kelly grid technique. Five new judges independently rated all 250 cards from 1 to 7 along five dimensions that emerged: warm-cold, funny-not funny, for a specific person-for anyone, in good taste-in poor taste, and romantic-unromantic. For each measure, we calculated interjudge reliability; Cronbach's alphas ranged from 0.74 to 0.91 . We calculated average ratings on each dimension for each card, and dummy coded objective features of the cards (e.g., belated or not).

We then created verbal descriptions of two card recipients: a close female neighbor and a male coworker whom the card giver does not know well. Figures 1 and 2 show how the information about the female neighbor's tastes was conveyed.

Seven independent judges then rated all available cards on quality (i.e., their fit) for each of the two recipients. Judges used a seven-point scale where higher values indicated a better fit. Cronbach's alpha of their ratings was 0.88 for the female neighbor task and 0.85 for the male coworker task, implying a high level of agreement across judges. Judges' ratings were averaged, and average ratings were used as the criterion measure for the quality of the chosen card, $Q$.

We derived the agent's $\hat{Q}$ values by regressing the judges' average ratings of the cards on the card feature dummy variables and the first set of judges' ratings of five card dimensions. We used these $\hat{Q}$ values in the ordered search conditions in experiments 1 and 2 . We ordered recommendations by predicted quality $\hat{Q}$ minus price in experiment 1 and $\hat{Q}$ in experiment 2 . Across the 250 cards, the correlation between a card's utility score and the rating by the average judge was good but not perfect -0.80 for the female neighbor and 0.77 for the male coworker. Therefore the ranking 
FIGURE 1

VERBAL DESCRIPTION OF THE FEMALE NEIGHBOR

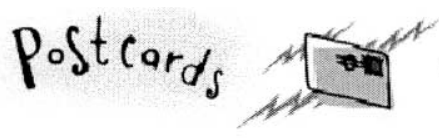

Imagine you have to send a funny birthday card to a close female neighbor of yours. This friend is married and in her $30 \mathrm{~s}$. Unfortunately, you have forgotten about her birthday and now even an electronic birthday card will arrive late.

She is the kind of person who notices these things, so you may want to look for a 'belated' card.

This neighbor, although not old at all, has a serious problem with age related humor. You definitely want to stay away from cards that feature age-related messages. However, other than that, she has a great sense of humor and would probably like a funny card, though she does not go for really tasteless humour.

Back

Next

FIGURE 2

GRAPHICAL DESCRIPTION OF THE FEMALE NEIGHBOR

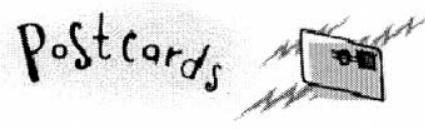

This screen is another way to help you find the card that best suits your neighbor. Based upon her description in the previous screen, we have compiled a list of important dimensions that determine how well the card "fits" your neighbor. The bar graph below shows the relative importance of these dimensions for finding the right card.

not for a specific birthday

not romantic

warm

for a specific person, a friend

belated

not age related

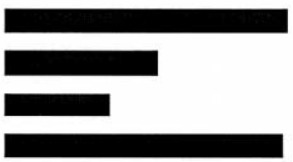

very

important

important

Back

Next 
FIGURE 3

EXAMPLE OF A CARD PREDICTED TO BE A GOOD FIT FOR FEMALE NEIGHBOR

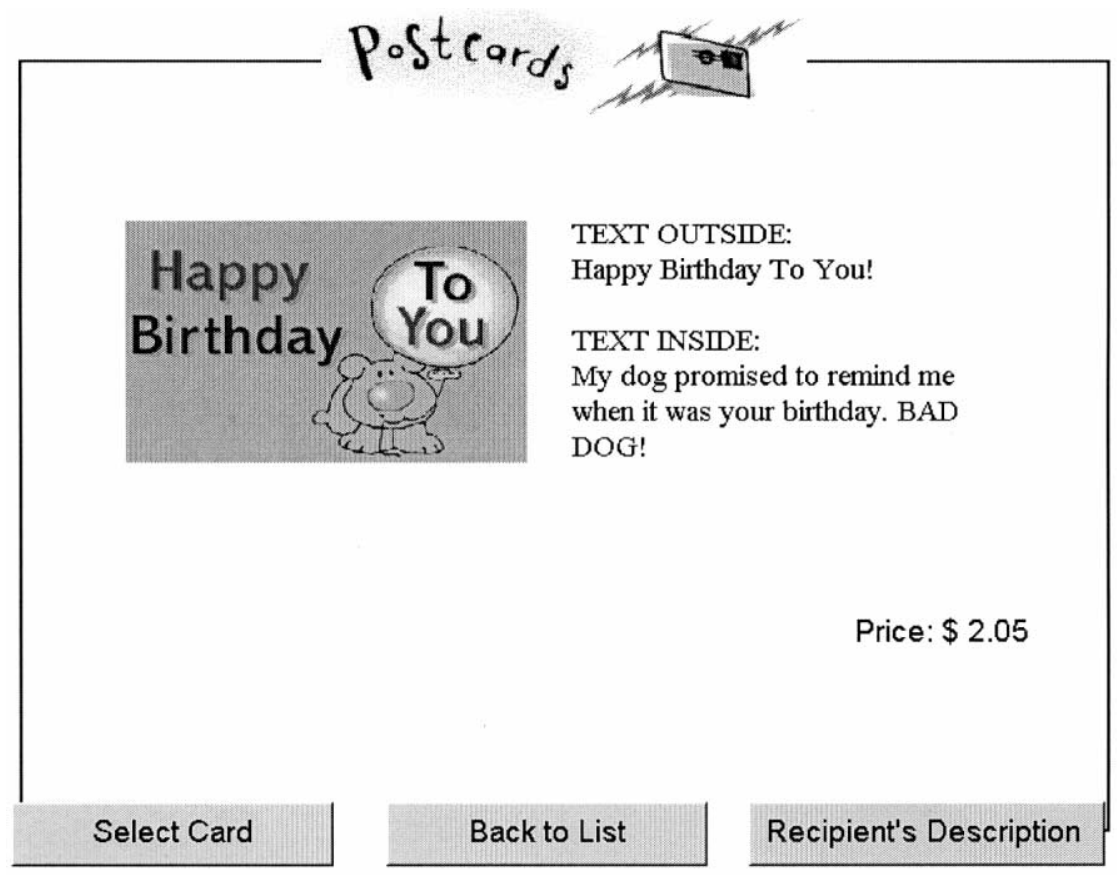

was a good but not perfect indication of the card's quality, $Q$.

Procedure. Sixty-four undergraduate students participated in this study in return for $\$ 5$ cash compensation and the opportunity to earn more money by performing well on the experimental task. Participants were randomly assigned to a condition. After starting the computer program, they read a cover story that described "e-your greetings," a new electronic greeting card service. Participants saw a verbal description of one of the recipients (see fig. 1) followed by a graphical representation of the recipient's importance weights (fig. 2). Next we told participants that the service's search engine had identified 50 alternatives that would be presented in a certain way. For one recipient, respondents were told that the 50 cards were ordered: "To make the search easier for you, alternatives are ranked from best to worst according to how closely the site's search tool thinks a card will match your [neighbor's/ coworker's] preferences. The cards that are shown first in the list are those that this model predicts should better fit your [neighbor's/coworker's] preferences. The model is not perfectly accurate, of course, but cards earlier in the list are, on average, rated by our judges as a better fit than those later in the list." In the Random condition, subjects were told, "e-your greetings has identified the following birthday cards for you. These alternatives are not ranked in any way. The list is simply a random assortment of birthday cards that e-your greetings has to offer."
Participants then saw a list of options characterized only by short, relatively meaningless titles (e.g., dog, flowers, etc.) chosen to reveal little information about the nature of the card. To view a specific card, subjects had to click on its highlighted title. This forced participants to view the card to assess its appropriateness for the recipient (see figs. 3 and 4). While searching, subjects always had access to the verbal description as well as a pictorial representation of the card recipient's importance weights. They saw no numerical overall quality score. After looking at a given card, participants could either go back to the list or select that specific card.

Clicking on a card also revealed its price. Prices were randomly assigned to each card and ranged between $\$ 1.50$ and $\$ 3.00$. We explicitly told participants that there was no correlation between price and quality and that they would be rewarded for picking a high quality card at a low cost. For a randomly determined trial in the study, the participant received the cash equivalent to judges' average rating of the chosen card minus the price of the card. Participants read an extensive description of the payoff scheme that included several numerical examples explaining the reward structure. In addition to their participation fee, participants took home between $\$ 0$ and $\$ 5$, with an average additional payment of $\$ 2.45$.

The search agent's ordering of options matched this incentive scheme by ranking alternatives according to the expected net value of each card. The agent used its prediction 
FIGURE 4

EXAMPLE OF A CARD PREDICTED TO BE A MEDIUM FIT FOR FEMALE NEIGHBOR

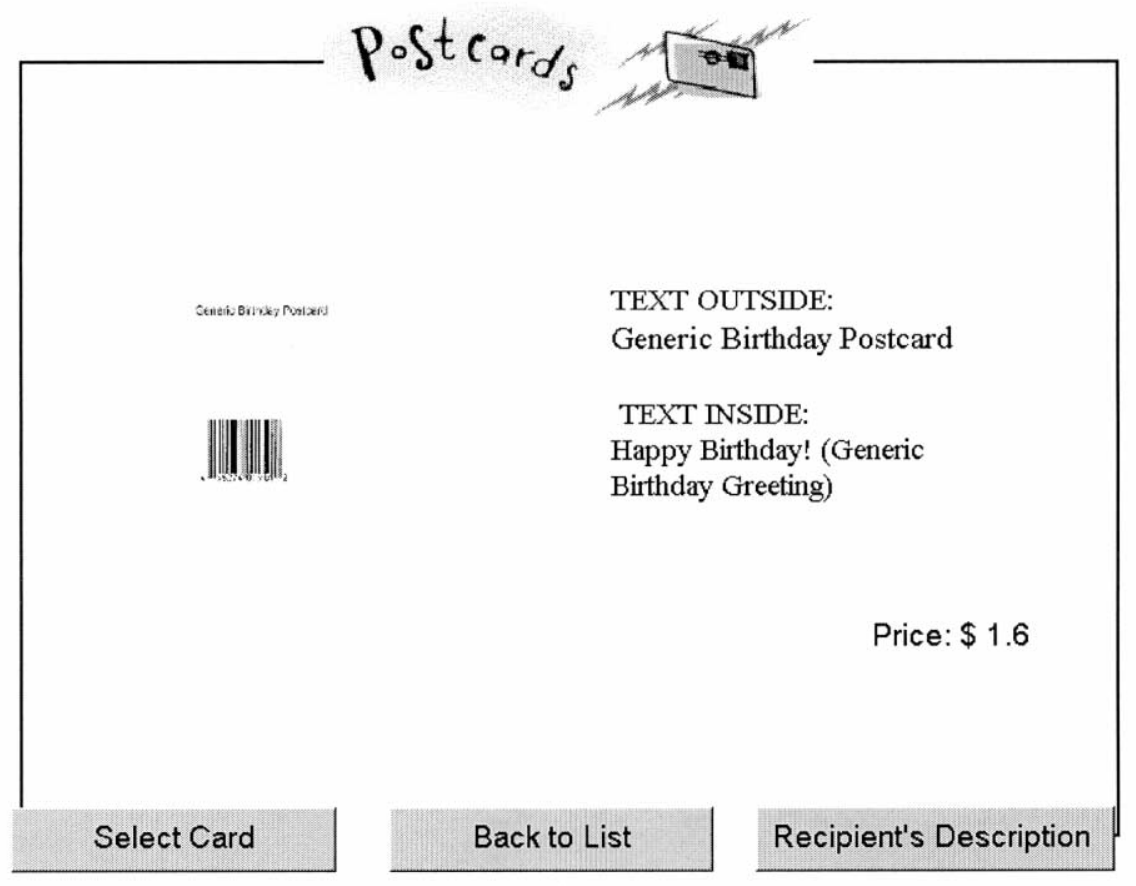

of the judges' ratings (regressing pretest judges' ratings of card appropriateness on card characteristics) net of price to order options. Therefore the rank order correlation between a card's quality and its position on an ordered list was high but not perfect. The expected net value calculated by the agent was an imperfect predictor of the actual payoff participants received. A participant's payoff was based on the judges' actual ratings minus the card's price (i.e., on $Q-$ $P$, not $\hat{Q}-P$ ).

Independent Variables. We used a 2 (Type of Search Agent $) \times 2$ (Assortment Size $) \times 2($ Order of Search $) \times$ 2 (Order of Recipient) mixed design. Type of Search Agent was a within-subjects factor. For one trial, alternatives were ordered according to the expected net value, and the 50 cards from the assortment predicted to be best were listed in order; for the other trial, a random sample of 50 cards from the assortment was presented in a random order. There were two between-subjects counterbalancing factors, Order of Search (Random-Ordered vs. Ordered-Random) and Order of Recipient (Neighbor, Coworker vs. Coworker, Neighbor). As expected, neither of these factors had significant effects, and they will not be discussed further.

Assortment Size was a two-level between subjects factor that varied the number of cards in the underlying assortment from which the 50 recommendations were drawn. The Large Assortment had all 250 cards. The Small Assortment was created by stratifying the Large Assortment on card quality and drawing a stratified random sample of 75 cards that matched it in quality mean and standard deviation. Each sample of 75 included the best card of the 250. In no case were subjects told anything about assortment size prior to shopping.

Dependent Measures. The key dependent variable was the price of the chosen card, which ranged from $\$ 1.50$ to $\$ 3.00$. We measured the quality score of the card the participant chose by the average rating the card received from the external judges.

\section{Results of Experiment 1}

Price Paid. Table 1 shows cell means for this experiment and for experiments 2 and 3. In line with hypothesis 1, participants paid lower prices for their choice when options were ordered $\left(M_{\mathrm{Or}}=\$ 2.06\right)$ than if no ordering was available $\left(M_{\mathrm{Ra}}=\$ 2.35\right), F(1,56)=17.6, p<.001$.

To test hypothesis 2 , we analyzed the effect of assortment size on prices paid in ordered search, using the price paid during the random search as a covariate (covariate $F(1,55)=3.6, p<.07$ ). (Assortment size does not influence price in random search, because it is equivalent to draw a random sample of 50 cards from the overall set of 250 cards or to draw a stratified random sample of 75 cards from the overall set of 250 and then to draw random sample of 50 cards from that sample of 75.) We found that, in ordered search, prices paid were marginally lower in the large assortment condition $\left(L S M_{\mathrm{Or}, N=250}=\$ 1.97\right)$ than in the small 
TABLE 1

OVERVIEW OF EXPERIMENTS AND RESULTS

\begin{tabular}{|c|c|c|c|c|c|c|c|c|c|c|c|c|c|}
\hline \multirow[b]{3}{*}{$\begin{array}{l}\text { Type of } \\
\text { search agent }\end{array}$} & \multicolumn{4}{|c|}{ Experiment 1: Assortment size ${ }^{a}$} & & & & \multicolumn{6}{|c|}{$\begin{array}{c}\text { Experiment } 3:^{c} \text { Principal's weight on } \\
\text { price }(a)\end{array}$} \\
\hline & \multicolumn{2}{|c|}{$\begin{array}{l}75 \text { (Small) } \\
(n=29)\end{array}$} & \multicolumn{2}{|c|}{$\begin{array}{c}250 \text { (Large) } \\
(n=35)\end{array}$} & \multicolumn{3}{|c|}{ Experiment $2^{\mathrm{b}}$} & \multicolumn{2}{|c|}{$\begin{array}{c}.2 \\
(n=13)\end{array}$} & \multicolumn{2}{|c|}{$\begin{array}{c}1 \\
(n=10)\end{array}$} & \multicolumn{2}{|c|}{$\begin{array}{c}5 \\
(n=13)\end{array}$} \\
\hline & $\mathrm{Ra}$ & Or & $\mathrm{Ra}$ & Or & $\begin{array}{c}\mathrm{Ra} \\
(n=22)\end{array}$ & $\begin{array}{l}\text { Or 1st time } \\
(n=43)\end{array}$ & $\begin{array}{l}\text { Or } 2 \mathrm{~d} \text { time } \\
(n=21)\end{array}$ & $\mathrm{Ra}$ & Or & $\mathrm{Ra}$ & Or & $\mathrm{Ra}$ & Or \\
\hline Mean price $(\$)$ & 2.4 & 2.2 & 2.4 & 2.0 & 2.6 & 2.3 & 2.1 & 102.5 & 115.9 & 100.5 & 67.8 & 94.7 & 64.6 \\
\hline Mean quality & 5.3 & 5.3 & 4.7 & 5.9 & 5.4 & 5.5 & 5.5 & 119.3 & 139.7 & 109.6 & 110.8 & 107.8 & 98.8 \\
\hline$a$ & \multirow{3}{*}{\multicolumn{4}{|c|}{$\begin{array}{l}1 \\
0 \\
\hat{Q}-P\end{array}$}} & \multirow{3}{*}{\multicolumn{3}{|c|}{$\begin{array}{l}1 \\
0 \\
\hat{Q}\end{array}$}} & \multirow{3}{*}{\multicolumn{6}{|c|}{$\begin{array}{l}.2,1,5 \\
\hat{Q}-\mathrm{aP}\end{array}$}} \\
\hline$\rho$ & & & & & & & & & & & & & \\
\hline Ordering on & & & & & & & & & & & & & \\
\hline
\end{tabular}

NOTE. $-\mathrm{Ra}=$ Random; Or $=$ Ordered.

aHypothesis 1, $P_{\mathrm{Or}}<P_{\mathrm{Ra}}$; hypothesis $2, P_{\mathrm{Or} \text {, Large Assortment }}<P_{\mathrm{Or} \text {, Small Assortment; }}$; hypothesis 3 , $Q_{\mathrm{Or} \text {, Large Assortment }}>Q_{\text {Or, Small Assortment }}$.

bHypothesis 1, $P_{\mathrm{Or}}<P_{\mathrm{Ra}}$; hypothesis $4, P_{\mathrm{Or}, 2 \mathrm{~d} \text { Trial }}<P_{\mathrm{Or}, 1 \text { st Trial }}<P_{\mathrm{Ra}}$.

${ }^{c}$ Hypothesis $5, P_{\mathrm{Or} a=0.2}>P_{\mathrm{Ra} a=0.2}$; hypothesis $5, P_{\mathrm{Or} a=1}<P_{\mathrm{Ra} a=1}$; hypothesis $5, P_{\mathrm{Or} a=5}<P_{\mathrm{Ra} a=5}$; hypothesis $6, Q_{\mathrm{Or} a=0.2}>Q_{\mathrm{Ra} a=0.2} ;$ hypothesis $6, Q_{\mathrm{Or} a=1}>$ $Q_{\text {Ra } a=1}$; hypothesis $6, Q_{\text {Or } a=5}<Q_{\text {Ra } a=5}$.

assortment condition $\left(L S M_{\mathrm{Or}, N=75}=\$ 2.17\right), \quad F(1,55)=$ $3.45, p<.07$.

Quality of the Chosen Card. Hypothesis 3 suggests that in the case of ordered search, size of the assortment will improve choice quality. Again, we analyzed the effect of assortment size on quality of the chosen option for the ordered trial and used the outcome from the random trial as a covariate (covariate $F(1,55)=0$ ). Supporting hypothesis 3, we found that when ordering was available, having access to a bigger underlying assortment improved the quality of the chosen option $\left(L S M_{\mathrm{Or}, N=250}=5.86\right.$, $\left.L S M_{\mathrm{Or}, N=75}=5.33\right), F(1,55)=4.99, p<.05$.

\section{Discussion of Experiment 1}

The primary purpose of experiment 1 was to test the hypothesis that lowering quality search costs by ordering will increase consumer price sensitivity rather than decrease it as would be expected from other mechanisms for reducing the cost of search for quality information. A secondary purpose was to show how ordering leverages size of a retailer's underlying assortment that would not pay dividends in the absence of ordering.

We first discuss results related to the second purpose. Alba et al. (1997) noted that without a good ordering agent, the consumer cannot benefit from increased size of assortment. Consistent with our hypotheses 2 and 3, we found that with a good ordering agent, consumers were able to choose better quality cards at lower prices when the underlying assortment was larger. The larger the underlying assortment being screened by the agent, the better the expected quality of the best option and the more similar in quality the top $n$ options in the list will be.

The most important result from experiment 1, though, is that subjects paid lower prices when card recommendations were ordered than when they were not. This finding appears to contrast with Lynch and Ariely (2000) who showed that making quality information easier to process decreases price sensitivity. Our mechanism of making quality information easier to process is conceptually different from theirs and thus leads to different outcomes because ours makes considered options more rather than less similar in quality. They lowered search costs for quality by providing deeper information with fewer mouse clicks; this leads to greater differentiation of considered options. Our manipulation of reducing search cost for quality was done via an ordering, and our conceptualization relies on order statistics. We ordered options according to their expected fit with the recipient net of price, thus screening out unsuitable alternatives, providing searchers with a more homogenous choice set in which price will play a bigger role when deciding between options.

While our finding suggests that screening tools make quality information easier to process and also decrease prices paid, we cannot separate two interpretations. In this study, alternatives were ordered according to the predicted net value, that is, a combination of price and quality information. Thus, while quality information was easier to process, so were prices (cf. Häubl and Murray 2003). The results in appendix A imply that any helpful sort, whether on a pricequality composite or on quality alone, will lead to lower prices. In experiment 2, we therefore seek to replicate our findings supporting hypothesis 1 in environments where the ordering is based on quality alone. We still expect that when ordering produces more similarity in quality among the best $n$ options, subjects will be more sensitive to price.

Our other purpose in experiment 2 is to investigate how repeated interactions with the agent's ordering affect the degree of support we find for hypothesis 1. Lynch and Ariely (2000) lowered search costs for quality by making it easier to understand differences among the wines they sold, thus lowering price sensitivity. They speculated in their discussion that such effects should only be found in initial periods. Once consumers had learned quality differences among wines, one should not expect in a second period to see an effect of shopping in an environment with high versus low 
search costs for quality. We hypothesize that the benefits from lowering quality-search costs via ordering will not disappear with repeated use. Rather, we hypothesize that consumers will learn over time that they can rely on the agent to provide high-quality recommendations and learn to achieve high quality at lower prices.

H4: Prices paid will be an inverse function of number of opportunities to use an ordered agent.

\section{EXPERIMENT 2: EFFECTS OF EXPERIENCE WITH THE ORDERED AGENT}

In experiment 2 we used a 3 (Sequence of Search) $\times 2$ (Order of Recipient) $\times 2$ (Trial) mixed design where 43 undergraduate subjects completed two searches. Trial (1 vs. 2) was a within-subjects factor. Subjects either had access to the agent's ordering in only one or in both trials. That is, they searched from either a random and an ordered list or from two ordered lists. Sequence of searches was a threelevel between-subjects factor (Ordered-Random, RandomOrdered or Ordered-Ordered). Order of recipient (NeighborCoworker or Coworker-Neighbor) varied between-subjects. In this study the underlying assortment was held constant across conditions. Everybody had a small size assortment $(N=75)$ and saw a list of 50 recommendations.

As in experiment 1, participants were rewarded for picking a good card at a low price, since they received additional payment for the net value (judges' rating minus price paid) of the chosen card. Unlike experiment 1 , however, the ordering of options in a recommended list was by the agent's predicted fit for the recipient $\hat{Q}$, not by net value $\hat{Q}-P$. Ordering on (predicted) quality alone will allow us to draw more definite conclusions about the effect of ordering on prices paid. We hope to show that ordering on predicted quality decreases average prices paid. Appendix A implies that similar findings should obtain for any helpful ordering.

All participants also completed an initial trial (trial 0) where ordering was random, searching for a birthday card for a friend's child. Response on this trial served as a between-subjects covariate, and the trial also discouraged curiosity-based search on the focal trials.

\section{Results of Experiment 2}

For the groups encountering both the random and the ordered search tools, we found neither a significant trial main effect nor a main effect for the sequence in which they performed these two searches. Averaging across the random and ordered trials, price paid and quality did not differ between Random-Ordered versus Ordered-Random sequences. We therefore collapsed conditions, treating it as if the random search always appeared in trial 1 and the ordered search always appeared in trial 2. This leaves us with two twolevel between-subjects factors, sequence of search (RandomOrdered vs. Ordered-Ordered) and sequence of recipients
(Coworker-Friend vs. Friend-Coworker) and a two-level within-subjects factor, Trial (1 vs. 2).

We wanted to reexamine the effects of ordering on participants' willingness to pay higher prices and to investigate how this might be modified by increased familiarity with the quality-ordering agent. In our design, some subjects are choosing with the benefit of two encounters with the ordered agent (trial 2 of Ordered-Ordered condition), some are choosing with one encounter (trial 1 of Ordered-Ordered or trial 2 of Random-Ordered), and some are choosing with no encounters (trial 1 of Random-Ordered). We use the prices paid on trial 0 as a covariate, accounting for each participant's unique willingness to pay $(F(1,38)=11.4, p<.01)$.

Hypothesis 4 states that prices paid will be an inverse function of the number of opportunities to use an ordered agent. We used a linear trend test to approximate this hypothesis of monotonicity (Dawes and Corrigan, 1974). Prices paid were highest in the Random condition when subjects had zero exposures to the ordered agent $\left(L S M_{\mathrm{Ra}-\mathrm{Or} \text { Trial } 1}=\$ 2.55\right)$, intermediate when they had one exposure $\left(L S M_{\mathrm{Ra}-\mathrm{Or} \text { Trial } 2_{2}=}=\right.$ $\left.\$ 2.34 ; L S M_{\text {Or-Or Trial } 1}=\$ 2.35\right)$, and lowest when they had two exposures $\left(L S M_{\text {Or-Or Trial } 2}=\$ 2.13\right)$. The linear trend of number of exposures was significant, $F(1,76)=9.55, p<$ .01 . The decrease was homogeneous moving from zero to one versus from one to two exposures, as evidenced by the nonsignificant quadratic trend, $F(1,76)=0$. Prices paid were marginally higher in the Random condition than the pooled one-exposure conditions, $F(1,76)=3.13, p<.08$. Similarly, prices paid were marginally lower in the two-exposure condition than in the pooled one-exposure conditions, $F(1,76)=3.24, p<.08$. If results are analyzed as a conventional ANOVA, we find that prices paid are lower in the Ordered-Ordered sequence than in the Random-Ordered sequence $(F(1,38)=5.82, p<.05)$, prices paid are lower on the second trial than on the first trial $(F(1,38)=4.10, p<$ $.05)$, and there is no Trial $\times$ Sequence interaction $(F(1,38)=0)$.

\section{Discussion of Experiment 2}

We found that even when alternatives were ordered only on predicted quality, consumers paid less with the benefit of the ordering. Consumers paid lower prices in ordered than in random search, and using the ordered search agent a second time decreased prices more than using it once. This reflects learning. This experience-based gain in ability to find a low price did not come at the expense of higher search or lower quality. Participants who experienced the ordered search agent twice did not search more or less than those first experiencing the agent, nor did they choose higher or lower quality $(F$ 's $<1)$.

\section{EXPERIMENT 3: EFFECTS OF THE PRICE-QUALITY RELATIONSHIP}

In experiment 3 , we relax the assumption that price and quality are independent and look at the implications for search when there is a positive relationship between price 


\section{FIGURE 5}

COMPARISON OF CONSUMER'S RELATIVE IMPORTANCE OF PRICE WITH PRICE-QUALITY TRADE-OFF IN MARKET

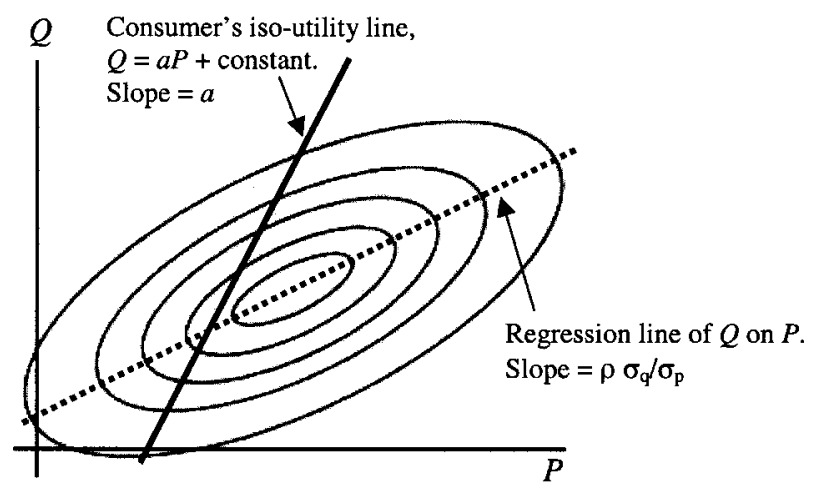

NotE.-The contour lines of the joint distribution (the ellipses) are drawn with $\rho=.6, \sigma_{\mathrm{q}}=\sigma_{\mathrm{p}}=1$. The iso-utility line $(Q-a P=$ constant $)$ is drawn with $a=5$, so it has the equation $Q=5 P+$ constant. This means that the relative importance of price is five times the importance of quality in the consumer's utility function. Utility is increasing as the iso-utility line moves to the northwest.

and quality, that is, higher quality items tend to be higher priced. We revisit the logic of hypothesis 1 , which predicted that searching an ordered list rather than a random list will result in lower prices being paid. Hypothesis 1 deduced effects of orderings based on quality or on quality net price for a weak (or no) relationship between price and quality. A richer story, taking into account a nonzero relationship between price and quality, shows that the key determinant of outcomes is the comparison of two slopes: the slope of the regression of quality on price and the slope that represents the price versus quality trade-off in the consumer's utility function.

If there is a strong relationship between price and quality, then ordering on quality alone will place the very high quality, very high priced items at the top of the list. The best item will depend on consumers' relative valuation of price and quality. If quality is much more important than price, then consumers will tend to select one of the highest quality items available. As price increases in importance, consumers will pick relatively lower quality items. The key distinction is between the slope of the association between price and quality in alternatives available in the market and consumers' perceived importance of price compared to quality.

We have modeled the strength of the relationship between price and quality in the market as the slope of the regression of quality on price in a bivariate normal distribution. This slope depends not only on the correlation $\rho$ between price and quality but also on the standard deviations of price and quality, $\sigma_{\mathrm{p}}$ and $\sigma_{\mathrm{q}}$. The expression for the slope of quality on price is given by $\rho \sigma_{\mathrm{q}} / \sigma_{\mathrm{p}}$ (Hays 1973, p. 630). We have constructed the value function with a weight of price parameter $a$, so that the consumer's value is $Q-a P$. For simplicity, we assigned a weight of one to quality. We define the relative importance of price as the ratio of the weight of price (a) to the weight of quality (1), that is, relative importance of price is $a(=a / 1)$. See figure 5. Likewise, we define the relative importance of quality as the ratio of the weight of quality to the weight of price, 1/a. In appendix A, we argue that a helpful ordering raises the consumer's reservation level $(Q-a P)$, then we derive the effects of a higher reservation level on price. Hypothesis 5 states those deductions, comparing the price effects of ordering by $\hat{Q}-a P$ with random ordering.

H5: Consumers will pay lower prices if the relative importance of price $(a)$ is greater than the slope of quality on price $\left(\rho \sigma_{\mathrm{q}} / \sigma_{\mathrm{p}}\right)$. Consumers will pay higher prices if the relative importance of price (a) is less than the slope of quality on price $\left(\rho \sigma_{\mathrm{q}} / \sigma_{\mathrm{p}}\right)$.

To derive analogous results for quality of the selected item, we flip the axes and look at the slope of the regression of price on quality $\left(\rho \sigma_{\mathrm{p}} / \sigma_{\mathrm{q}}\right)$. It is the comparison of this slope with the relative importance of quality $(1 / a)$ that determines whether ordering increases or reduces the level of quality of the selected item. See figure 6. In appendix B, we derive the effects of ordering on the expected quality of the selected option. Hypothesis 6 states those deductions, comparing the quality effects of ordering by $\hat{Q}-a P$ with random ordering.

H6: Consumers will choose higher quality items if the relative importance of quality $(1 / a)$ is greater than the slope of price on quality $\left(\rho \sigma_{\mathrm{p}} / \sigma_{\mathrm{q}}\right)$. Consumers will choose lower quality items if the relative importance of quality $(1 / a)$ is less than the slope of price on quality $\left(\rho \sigma_{\mathrm{p}} / \sigma_{\mathrm{q}}\right)$.

The two hypotheses together create three possible conditions in the presence of ordering: lower price, higher qual-

\section{FIGURE 6}

COMPARISON OF CONSUMER'S RELATIVE IMPORTANCE OF QUALITY WITH PRICE-QUALITY TRADE-OFF IN MARKET

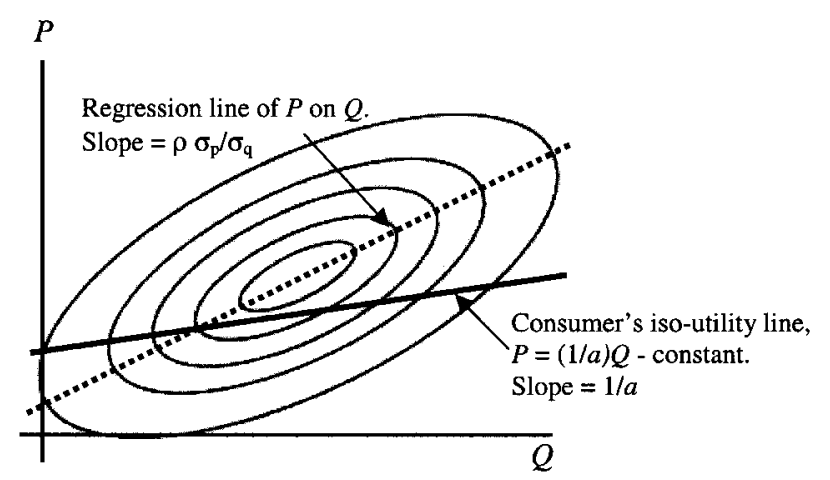

NotE.-The contour lines of the joint distribution (the ellipses) are drawn with $\rho=.6, \sigma_{\mathrm{q}}=\sigma_{\mathrm{p}}=1$. The iso-utility line $(Q-a P=$ constant $)$ is drawn with $a=5$, so it has the equation $P=.2 Q-$ constant. Utility is increasing as the iso-utility line moves to the southeast. 
FIGURE 7

EXPERIMENT 3-EXAMPLE OF A HOTEL REPRESENTATION

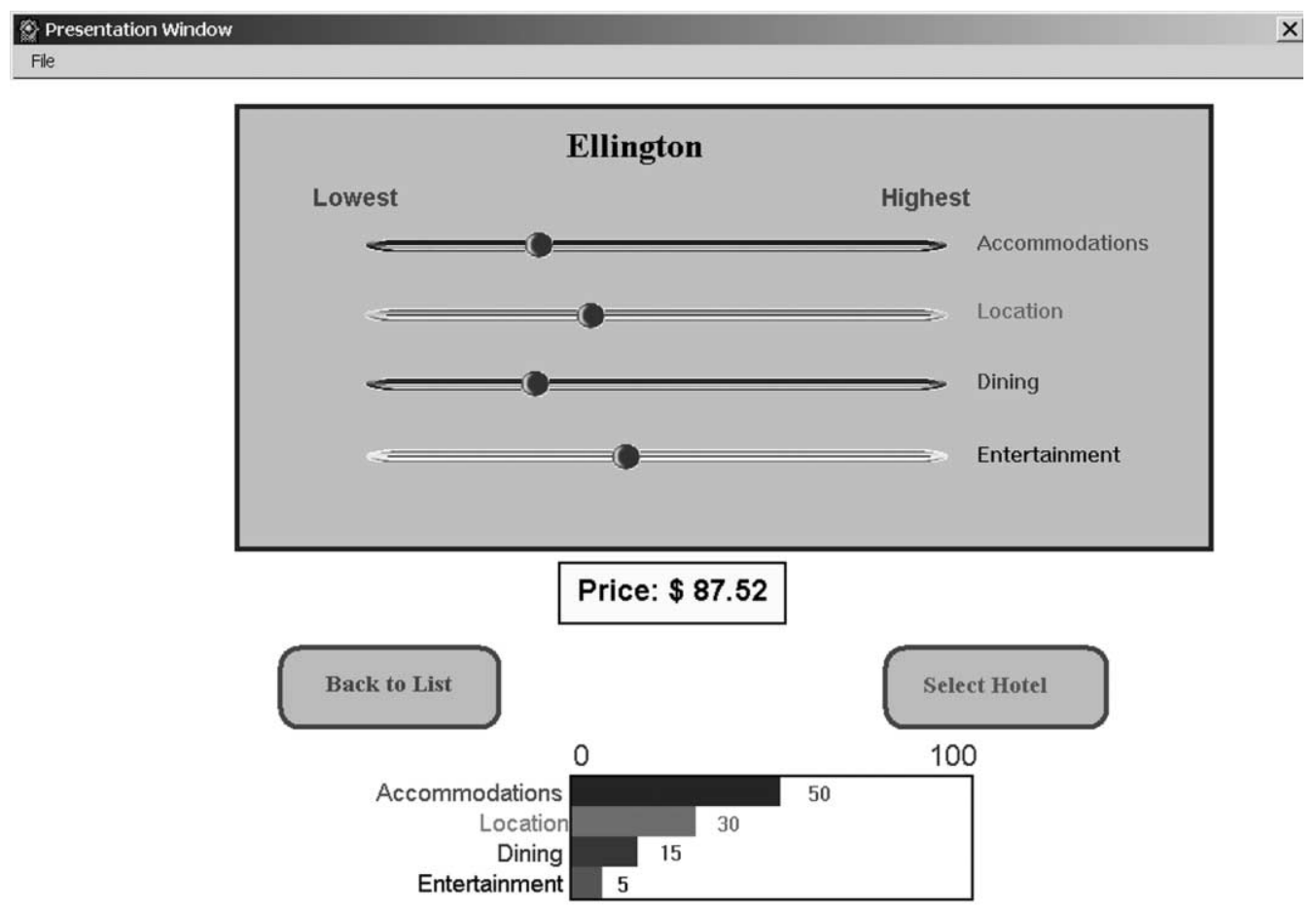

ity; higher price, higher quality; and lower price, lower quality. The fourth combination (higher price, lower quality) is not possible because we are considering only value functions that treat quality as a positive attribute and price as a negative attribute.

The special case of hypotheses 5 and 6 in which the correlation between price and quality is zero gives the predictions that price will decrease and quality will increase with the use of an ordered list. This zero correlation case was examined in experiments 1 and 2 reported above. We will return to these results after experiment 3 .

\section{Method}

Overview. Thirty-six paid student volunteers participated in a 3 (Relative Importance of Price in the reward function) $\times 2$ (Type of Search Agent) $\times 2$ (Order of Search) mixed design. The task used was a principal-agent task, and participants were rewarded according to the principal's overall reward function, $Q-a P$, a combination of choice quality and price. The relative importance of price, $a,(0.2,1,5)$ was a between-subjects factor that described the principal's weight for price relative to quality. A larger value of $a$ indicated greater emphasis placed on price relative to quality. Type of Search Agent (Random, Ordered) was a withinsubjects factor. Participants performed one trial in which options were ordered according to an imperfect prediction of their payoff function $(\hat{Q}-a P)$; in the other trial options were random draws from the underlying inventory. Order of Search (Random-Ordered, Ordered-Random) was a between-subjects counterbalancing factor. Other parameters of our analytical model were held constant across conditions. The strength of the association between price and quality $(\rho)$ was set to be 0.6 and the ratio of $\sigma_{\mathrm{q}}$ to $\sigma_{\mathrm{p}}$ was held constant at one for all conditions.

Hypothesis 5 predicts that ordering leads to lower prices compared to a random list if $a$ is larger than $\rho \sigma_{\mathrm{q}} / \sigma_{\mathrm{p}}$ and to higher prices if $a$ is smaller. With ordering we therefore expect lower prices for conditions for $a=1$ or $a=5$ and higher prices for $a=0.2$.

Hypothesis 6 predicts that ordering leads to higher quality choices when $1 / a \geq \rho \sigma_{\mathrm{p}} / \sigma_{\mathrm{q}}$. For the values chosen in this experiment, this condition holds for $a=0.2$ and $a=1$. Therefore we predict ordering to lead to higher quality choices for conditions for $a=0.2$ or $a=1$. Ordering should lead to lower quality choices for $a=5$.

Stimulus Creation. As before, we used a principalagent task, but we chose a domain in which price and quality are believably positively correlated, that is, a domain with vertical differentiation. In experiment 3 we asked participants to search for and choose a hotel for another person. The principal's preferences for hotels and hotel options were described to participants along four attributes (accommodations, location, dining, and entertainment). See figure 7. Participants searched for a different principal in the first trial 
than in the second. In the first trial the principal's weights were always 50 for accommodation, 30 for location, 15 for dining, and 5 for entertainment. In the second trial, the principal's weights were $30,5,50,15$, respectively.

To create an inventory of 1,000 hotels, we drew independent values of all four attributes from a normal distribution with a mean of 50, a standard deviation of 15 , and a range of 0 to 100 . We computed an overall quality value $(Q)$ for each hotel by combining the four attribute values with the principal's preference weights. Overall quality values for each principal were rescaled to have a mean of 100 and a standard deviation of 15 . We created an imperfect prediction $(\hat{Q})$ of the true quality $(Q)$ by calculating a quality value omitting the second most important attribute. The predicted and true quality values were correlated 0.88 .

Each hotel came at a certain price. The correlation between price and quality in this environment was set at a moderate level of 0.6 for all conditions. Prices had a mean of 100 and, conditional on quality, were drawn from a normal distribution with standard deviation 12 .

Procedure. We randomly assigned participants to one of six conditions: Relative Importance of Price $(3) \times$ Order of Search Agent (2). They began by reading a description of the principal's preferences as well as of the way hotels would be described in the study. Participants then read an extensive explanation of the way any extra payment would be calculated. All subjects received base pay of $\$ 5$ for participation. The extra payment was determined by participants' choices in the experiment, using a payoff function of $Q-a P$. To ensure comprehension, participants were given several examples of hotel descriptions and prices and were shown how choosing a certain hotel would affect their extra pay. Across conditions, all participants also faced a $\$ 1$ search cost per new option inspected. Finally, participants were endowed with either a pool of money or a debt depending on which price-quality weighting scheme (i.e., $a$ ) they faced. This endowment was chosen such that just randomly picking an option from the selection would in expectation yield no positive or negative extra pay.

Participants were told that one of the two trials would be chosen at random to determine their payoff. In reality, for people in the $a=0.2$ and $a=1$ conditions, the ordered trial was chosen to determine their payoff; participants in the $a=5$ condition were paid for their performance in the random trial. We chose this payoff scheme to equate average payoffs between participants. Extra payments were capped at $\$ 3$ and had a lower bound of $\$ 0$ so that no one lost money.

Before each trial, participants read a description of how the options were ordered. In the random trial, participants were informed that options were just a random assortment of the overall inventory. For each participant a stratified random sample of 50 options was drawn from the inventory of 1,000 options.

In the ordered trial, participants read a description that explained that options were ordered according to how well the search engine expects each hotel to fit the principal's preferences. They were told that while this ordering is not perfect, options higher up on the list were on average better than options further down on the list. Options were ordered by their expected quality minus $a$ (relative importance of price) times the price of the hotel $(\hat{Q}-a P)$. This ordering was highly but not perfectly correlated with the true payoff function participants faced $(Q-a P)$. Participants encountered the 50 options that were predicted to be best with respect to the overall utility function of the principal $(\hat{Q}-a P)$.

Participants made two bookings for two different principals, were debriefed, paid, and dismissed. On average, participants took 10 minutes to complete the study.

\section{Results of Experiment 3}

The experimental design allowed us to test all three of the cases: ordering causes price to decrease and quality to increase compared to a random list $(a=1)$, ordering causes price to decrease and quality to decrease $(a=5)$, and ordering causes price to increase and quality to increase $(a=.2)$. We found significant support for five of our six predictions.

Prices Paid. There was a significant interaction between ordering and importance of price in the reward function $(F(2,30)=24.07, p<.001)$ as predicted by hypothesis 5 . When quality was more important than price $(a=0.2)$, prices were higher when options were ordered $\left(M_{a=0.2, \text { Or }}=\$ 115.9\right)$ than when options were drawn at random $\left(M_{a=0.2, \mathrm{Ra}}=\$ 102.5\right)$, supporting hypothesis 5, $F(1,11)=9.51, p<.02$. When quality and price were equally important $(a=1)$, prices were lower when options were ordered $\left(M_{a=1, \text { or }}=\$ 67.8\right)$ compared to trials in which options were drawn at random $\left(M_{a=1, \mathrm{Ra}}=\$ 100.5\right)$ as predicted by hypothesis $5, F(1,8)=18.25, p<.01$. Finally, the simple effect of ordering was also significant when price was more important than quality in the utility function of the principal $(a=5, F(1,11)=41.84, p<.001)$. Ordering options led to lower prices $\left(M_{a=5, \text { Or }}=\$ 64.6\right)$ than presenting participants with a random draw of options $\left(M_{a=5, \mathrm{Ra}}=\$ 94.7\right)$, supporting hypothesis 5 .

Quality of the Chosen Option. There was a significant interaction between ordering and importance of price in the reward function, or, equivalently, between ordering and the ratio of the importance of quality to price, $1 / a$, $(F(2,30)=12.1, p<.001)$, as predicted by hypothesis 6 . When quality was much more important than price $(a=$ $0.2)$, the simple effect of ordering was significant $(F(1,11)=30.08, p<.001)$, indicating that quality of the chosen option was much higher when options were ordered $\left(M_{a=0.2, \text { Or }}=139.7\right)$ as compared to when options were a random draw $\left(M_{a=0.2, \mathrm{Ra}}=119.3\right)$. This agrees with hypothesis 6.

Hypothesis 6 also predicted that the quality of the chosen option would be greater when options were ordered as opposed to random draws for $a=1$. The simple effect of ordering was not significant when quality and price were 
equally important $\left(M_{a=1, \mathrm{Or}}=110.8, \quad M_{a=1, \mathrm{Ra}}=109.6\right.$, $F(1,8)=0.06, p>.8)$. Finally, in line with hypothesis 6 , when price was much more important than quality $(a=5)$, quality of the chosen option was lower when options ordered $\left(M_{a=5, \text { Or }}=98.8\right)$ as opposed to when they were a random $\operatorname{draw}\left(M_{a=5, \mathrm{Ra}}=107.8\right), F(1,11)=5.01, p<.05$.

\section{Discussion of Experiment 3}

Overall, this experiment supports the predictions about the interaction between ordering and the weight of price in the consumer's value function derived from our analytical model. Compared to a random list, ordering on an imperfect price-quality composite leads to higher prices being chosen when price is less important. The same ordering leads to lower price choices when price is more important than quality. Likewise, ordering on an imperfect price-quality composite leads to a lower quality product being chosen when quality is less important, but to higher quality choices when the relative weight of quality to price exceeds the slope of the association between price and quality in alternatives available in the market.

The zero correlation case studied in experiments 1 and 2 is a special case of this general model. From our model it follows that in the zero correlation case, for any positive $a$, ordering should lead to higher quality choices and lower prices paid. In experiments 1 and 2, we do find the predicted results with respect to prices; when price and quality are uncorrelated, ordering leads to lower prices paid. However, only experiment 1 offers support for the prediction that ordering will also lead to higher quality choices. When price and quality are equally important $(a=1)$, neither experiment 2 with zero price-quality correlation nor experiment 3 with positive price-quality correlation produce the predicted effects on quality. Overall, however, five of the six hypotheses deduced from our framework were supported. The theory presented here did well in predicting the nuanced effects that ordering will have on quality and price of the chosen option, while taking into account environmental factors such as price-quality correlations as well as individual difference factors such as the consumer's relative importance of price.

\section{GENERAL DISCUSSION AND CONCLUSION}

A good quality-screening tool (smart agent) can be boon to consumers in navigating the vast array of choices available in many product categories. Truly smart screening tools can forecast the consumer's perceived attractiveness of products not yet inspected and present a list ordered from the most to the least promising. Such tools may be the most important vehicles for reducing the cost of search for quality information via electronic shopping (Alba et al. 1997).

Other methods of improved access to quality information have been shown to decrease price sensitivity. Giving consumers more information about quality differentiates products and decreases the relative importance of price, as pointed out in the advertising literature and recent work on on-line shopping. Lynch and Ariely (2000) examined the effects of reducing search cost for quality information by comparing conditions in which detailed information was more easily accessible (deeper information, fewer mouse clicks) to conditions in which it was less accessible. They found that the lower search costs for quality information decreased price sensitivity.

Decreasing search costs for quality information by the screening and sorting mechanism that we investigate has the opposite effect on differentiation and price sensitivity. A good sorting tool will increase price sensitivity in a wide range of conditions. It might seem a priori that screening on quality would increase the weight of quality relative to price in consumers' decision making. However, we maintain that a good screening tool does two things to drive down price. First, it produces an ordered list oversampling from the more attractive options. Second, these options will tend to be more similar in overall quality valuation compared to randomly selected items, making consumers less willing to pay a large premium to purchase a more preferred option. Therefore, not only do quality-screening agents improve the quality of the chosen options and reduce decision effort (Häubl and Trifts 2000), but they also permit the consumer to pay a lower price. This is true even when the agent screens on quality alone, as in experiment 2.

Moreover, when ordering lowers search costs for quality, the benefits do not dissipate with repeated choice. One would not expect similarly persistent effects of lower search costs from deeper information and fewer mouse clicks (cf. Lynch and Ariely 2000). In experiment 2, repeated use decreased the price consumers paid.

We showed in experiment 1 that quality screening affects consumers' benefit from retailer investments in larger assortments. With screening, larger underlying assortments allow consumers to buy higher quality items for cheaper prices than when assortments are smaller. We interpret this to be driven by greater substitutability of the top options from a larger underlying assortment. These results imply that retailer investments in size of the underlying assortment need to be accompanied by parallel investments in screening and personalization technology.

The preceding conclusions hold when price and quality are uncorrelated as is true in horizontally differentiated markets. Now consider how the conclusions about prices in the presence of ordering change when one moves to vertically differentiated markets, in which higher quality goods have higher prices on average. If the market trade-off between price and quality (i.e., how much additional quality an incremental unit of price buys) is less than a consumer's own trade-off between price and quality, then that consumer will tend to buy lower priced products when faced with a ranked list compared to a random list of options.

Results from the model show that prices will decrease with quality screening when the consumer's relative importance of price (compared to quality) exceeds the slope of the regression of quality on price available in the market. Quality screening should increase quality selected whenever 
the relative importance of quality (compared to price) exceeds the slope of the regression of price on quality. (Note that both of these conditions will always hold in horizontally differentiated markets with zero price-quality correlation.) Experiment 3 strongly supported our deductions about conditions under which ordering should increase prices and quality, decrease prices and quality, or increase quality while decreasing prices. Access to ordering will have opposite effects on two segments: those who value quality more and price less than the overall market and those who value quality less and price more than the overall market. Ordering will cause the former group to buy higher priced, higher quality goods, but will drive the latter group "down market" to lower priced, lower quality goods.

Surprisingly, any helpful ordering will have these effects. For example, the conclusions hold when the ordering uses an imperfect measure of quality (as in all three experiments) as well as when the ordering does not reflect the consumer's relative weights of price and quality (as in experiment 2). In experiment 2, options were ranked on the imperfect measure of quality alone, but the consumer's utility function was quality net price. A reviewer noted that our framework implies that with uncorrelated price and quality, sorting products by price (low to high) should cause consumers to choose higher quality items (not just lower priced) items, compared to the case with no sorting. Because it is so much easier to sort on price than on quality, this consequence has immediate practical implications.

The research reported here highlights the need for future work of three types. First, the analytic model has rich untested implications for how the net effect of screening on quality, and prices will depend on all of the terms in the model. For example, holding constant the price-quality correlation and the consumer's utility function, changes in the variance of price and quality in the marketplace will change the slopes $\left(\rho \sigma_{\mathrm{p}} / \sigma_{\mathrm{q}}\right.$ and $\left.\rho \sigma_{\mathrm{q}} / \sigma_{\mathrm{p}}\right)$ that determine whether screening should increase or decrease quality chosen and prices paid.

Second, by comparing random to imperfectly ordered conditions, this research implies that screening's benefit to consumers increases with the strength of the correlation between expected utility and ordinal position in a list. We need to understand how to improve quality screening via better personalization techniques (Ansari and Mela, 2003; Ariely, Lynch, and Aparecio, forthcoming).

Third, prices in this study were entirely exogenous. Like almost all experimental consumer research, we model the behavior of buyers and not of sellers. We did not represent how seller behavior is influenced by changes in buyer response or by improvements in information flows into consumer markets (cf. Moorman and Slotegraaf 1999). In real markets, prices paid would be a function of the behavior of buyers and sellers, both of whom may be strategic. Repeated use of the screening agent allows the consumer to get better prices without sacrificing quality. However, consumers can conceal their true preferences in order not to be exploited (cf. Feinberg, Krishna, and Zhang, 2002).
On the sellers' side, providing helpful orderings may increase consumer satisfaction and retention, but it may train consumers to be more price-sensitive, as in work on the long term effects of price promotions (Mela, Gupta, and Lehmann 1997). Future work is needed to understand the implicit incentives to sellers to provide personalized quality screening. Will retailers use quality screening as a way to intensify price competition among the manufacturers they carry? Or will retailers conclude that quality-screening tools will reduce their own ability to sell merchandise at full margin? How does this depend upon the price-quality correlation prevailing in the marketplace and its relation to the weight consumers place on price versus quality in their utility functions? Many open questions remain that can be answered by consumer researchers with different disciplinary skills.

\section{APPENDIX A}

This appendix contains additional support for hypothesis 1 , that is, sorting on quality or quality net price leads to lower prices. To see that sorting leads to lower prices, we look at the expected price paid, accounting for the difference in behavior due to the ordered and random lists. The ordered list allows the consumer to be choosier in the sense of having a higher reservation value (or threshold) of $Q-a P$, which dictates when to stop searching and to purchase. Hypothesis 1 is then true if the expected price is decreasing in the threshold.

We now investigate the conditions such that $E(P \mid Q-$ $a P \geq b)$ is decreasing in the threshold $b$. To find the expected value of price given the net value $Q-a P$ exceeds a threshold $b$, we integrate over possible values of $b$, denoting the conditional probability density function of $b^{\prime}$ as $f\left(b^{\prime} \mid b^{\prime} \geq\right.$ $b)$. That gives $E(P \mid Q-a P \geq b)=\int_{b}^{\infty} E(P \mid Q-a P=$ $\left.b^{\prime}\right) f\left(b^{\prime} \mid b^{\prime} \geq b\right) d b^{\prime}$. If $E(P \mid Q-a P=b)$ is decreasing in $b$, then $\int_{b}^{\infty} E\left(P \mid Q-a P=b^{\prime}\right) f\left(b^{\prime} \mid b^{\prime} \geq b\right) d b^{\prime}$ is decreasing in $b$. As $b$ increases, larger values of $E(P \mid Q-a P=b)$ are removed from the weighted average that makes up $E(P \mid Q-a P \geq b)$, so $E(P \mid Q-a P \geq b)$ goes down. Likewise, if $E(P \mid Q-a P=b)$ is increasing in $b$, so is $E(P \mid$ $Q-a P \geq b)$.

For a bivariate normal (BVN) distribution over $P$ and $Q$, with parameters $\mu_{\mathrm{p}}, \mu_{\mathrm{q}}, \sigma_{\mathrm{p}}, \sigma_{\mathrm{q}}$, and $\rho$,

$$
\begin{aligned}
& E(P \mid Q-a P=b)= \\
& \quad-\frac{\left(b-\mu_{q}\right)\left(a \sigma_{p}-\rho \sigma_{q}\right) \sigma_{p}+\mu_{p} \sigma_{q}\left(a \rho \sigma_{p}-\sigma_{q}\right)}{a^{2} \sigma_{p}^{2}-2 a \rho \sigma_{p} \sigma_{q}+\sigma_{q}^{2}} .
\end{aligned}
$$

This expression is derived from the conditional mean of a BVN random variable, the expected value of one of the variables given the other one is held constant, $E(x \mid y)=$ $\mu_{x}+\rho\left(\sigma_{x} / \sigma_{y}\right)\left(y-\mu_{y}\right)$. Assuming $P$ and $Q$ are BVN, it follows that $Q-a P$ is normal, and $P$ and $Q-a P$ are BVN.

This expression for $E(P \mid Q-a P=b)$ is decreasing in $b$ if and only if $\left[\left(a \sigma_{p}-\rho \sigma_{q}\right) /\left(a^{2} \sigma_{p}^{2}-2 a \rho \sigma_{p} \sigma_{q}+\sigma_{q}^{2}\right)\right] \geq 0$. The denominator is always positive (it is greater than $\left[a \sigma_{p}-\right.$ $\left.\sigma_{q}\right]^{2}$, which is positive). The numerator is positive if and 
only if $a \sigma_{p}-\rho \sigma_{q} \geq 0$ or $\left(\rho \sigma_{q} / \sigma_{p}\right) \leq a$. This last statement is equivalent to the slope of $Q$ on $P$ being less than $a$, the slope of the reward function.

We conclude that if there is a not-too-strong positive relationship between $Q$ and $P$, then using a higher $Q-a P$ threshold decreases average price paid; if the positive relationship between $Q$ and $P$ is very strong, then using a higher $Q-a P$ threshold increases average price paid.

\section{APPENDIX B}

In this appendix, we extend the analysis from appendix A to look at the effects of the relationship between the distribution on price and quality (i.e., the strength of the relationship) and the importance of price in the value function (the parameter $a$ ) on quality.

We use the same procedure as in appendix A to look at the effect of ordering on expected quality. As in appendix $\mathrm{A}$, we model the difference between the ordered and random condition with a higher stopping value in the ordered condition and look at the condition for which $E(Q \mid Q-$ $a P \geq b)$ is increasing in $b$. For $P$ and $Q$ bivariate normal (once again using the conditional mean of a BVN),

$$
\begin{aligned}
& E(Q \mid Q-a P=b)= \\
& \frac{\left(b+a \mu_{p}\right)\left(\sigma_{q}-a \rho \sigma_{p}\right) \sigma_{q}+a \mu_{q} \sigma_{p}\left(a \sigma_{p}-\rho \sigma_{q}\right)}{a^{2} \sigma_{p}^{2}-2 a \rho \sigma_{p} \sigma_{q}+\sigma_{q}^{2}},
\end{aligned}
$$

which is increasing in $b$ for $\sigma_{q}-a \rho \sigma_{p} \geq 0$, or $\left(\rho \sigma_{p} / \sigma_{q}\right) \leq$ $(1 / a)$. If the last condition holds, then increases in the threshold increase the quality of the chosen item.

[David Glen Mick served as editor and Donald R. Lehmann served as associate editor for this article.]

\section{REFERENCES}

Alba, Joseph, John G. Lynch, Jr., Barton Weitz, Chris Janiszewski, Richard Lutz, Alan Sawyer, and Stacy Wood (1997), "Interactive Home Shopping: Consumer, Retailer, and Manufacturer Incentives to Participate in Electronic Marketplaces," Journal of Marketing, 61 (July), 38-53.

Anders, George (1998), "Cybersqueeze: Comparison Shopping Is the Web's Virtue - unless You're a Seller," Wall Street Journal, July 23, A1.

Ansari, Asim and Carl Mela (2003), "e-Customization,” Journal of Marketing Research, 40 (May), 131-145.

Ariely, Dan, John G. Lynch, Jr., and Manuel Aparicio (forthcoming), "Learning by Collaborative and Individual-Based Recommendation Agents," Journal of Consumer Psychology.

Bakos, Yannis (1997), "Reducing Buyer Search Costs: Implications for Electronic Marketplaces," Management Science, 43 (December), 1676-1692.

Boulding, William, Eunkyu Lee, and Richard Staelin (1994), "Mastering the Mix: Do Advertising, Promotion, and Sales Force Activities Lead to Differentiation?" Journal of Marketing Research, 31 (May), 159-172.

Brynjolfsson, Erik and Michael Smith (2000), "Frictionless Com- merce? A Comparison of Internet and Conventional Retailers," Management Science, 46 (April), 563-585.

David, Herbert A. (1981), Order Statistics, New York: John Wiley $\&$ Sons.

Dawes, Robyn M. and Bernard Corrigan (1974), "Linear Models in Decision Making," Psychological Bulletin, 81 (2), 97-106.

Degeratu, Alexandru, Arvind Rangaswamy, and Jianan Wu (2000), "Consumer Choice Behavior in Online and Traditional Supermarkets: The Effects of Brand Name, Price, and Other Search Attributes," International Journal of Research in Marketing, 17 (1), 55-78.

Ehrlich, Isaac and Lawrence Fisher (1982), "The Derived Demand for Advertising: A Theoretical and Empirical Investigation," American Economic Review, 72 (June), 366-388.

Feinberg, Fred, Aradhna Krishna, and John Z. Zhang (2002), "Do We Care What Others Get? A Behaviorist Approach to Targeted Promotions," Journal of Marketing Research, 39 (August), 277-291.

Gershoff, Andrew and Patricia M. West (1998), "Using a Community of Knowledge to Build Intelligent Agents," Marketing Letters, 9 (January), 835-847.

Gove, Alex (1999), "Margin of Error: Internet Retailers Ponder a World of Zero Gross Profit Margins," Red Herring (February), 140 .

Häubl, Gerald and Kyle B. Murray (2003), "Preference Construction and Persistence in Artificial Marketplaces: The Role of Electronic Recommendation Agents," Journal of Consumer Psychology, 13 (1-2), in press.

Häubl, Gerald and Valerie Trifts (2000), "Consumer Decision Making in Online Shopping Environments: The Effects of Interactive Decision Aids," Marketing Science, 19 (Winter), 4-21.

Hauser, John and Birger Wernerfelt (1990), "An Evaluation Cost Model of Consideration Sets," Journal of Consumer Research, 16 (March), 393-408.

Hays, William L. (1973), Statistics for the Social Sciences, 2d ed., New York: Holt, Rinehart \& Winston.

Kaul, Anil and Dick Wittink (1995), "Empirical Generalizations about the Impact of Advertising on Price Sensitivity and Price," Marketing Science, 14 (3), 151-160.

Kohn, Meir and Steven Shavell (1974), "The Theory of Search," Journal of Economic Theory, 2 (9), 93-123.

Konstan, Joseph A., Bradley N. Miller, David Maltz, Jonathan Herlocker, Lee R. Gordon, and John Riedl (1997), "GroupLens: Applying Collaborative Filtering to USENET News," Communications of the ACM, 40 (March), 77-87.

Kuttner, Robert (1998), "The Net: A Market Too Perfect for Profits," Business Week (May 11), 20.

Lal, Rajiv and Miklos Sarvary (1999), "When and How Is the Internet Likely to Decrease Price Competition?" Marketing Science, 18 (4), 485-503.

Lynch, John G., Jr. and Dan Ariely (2000), "Wine Online: Search Cost and Competition on Price, Quality, and Distribution," Marketing Science, 19 (Winter), 83-103.

Mela, Carl F., Sunil Gupta, and Donald R. Lehmann (1997), “The Long-Term Impact of Advertising and Promotions on Consumer Brand Choice," Journal of Marketing Research, 34 (2), 248-261.

Mitra, Anusree and John G. Lynch, Jr. (1995), “Toward a Reconciliation of Market Power and Information Theories of Advertising Effects on Price Elasticity," Journal of Consumer Research, 21 (4), 644-659.

(1996), "Advertising Effects on Prices Paid and Liking for Brands Selected," Marketing Letters, 7 (1), 19-29. 
Moorman, Christine and Rebecca J. Slotegraaf (1999), “The Contingency Value of Complementary Capabilities in Product Development," Journal of Marketing Research, 36 (May), 239-257.

Moorthy, Sridhar, Brian Ratchford, and Debabrata Talukdar(1997), "Consumer Information Search Revisited: Theory and Empirical Analysis," Journal of Consumer Research, 23 (March), 263-277.

Mosteller, Frederick and Robert Rourke (1973), Sturdy Statistics, Reading, MA: Addison-Wesley.

Quelch, John A. and Lisa R. Klein (1996), "International Business and the Internet," Sloan Management Review, 37 (3), 60-75.

Roberts, John and James Lattin (1991), "Development and Testing of a Model of Consideration Set Composition," Journal of Marketing Research, 28 (November), 429-440.
Rosen, Sherwin (1978), "Advertising, Information, and Product Differentiation," in Issues in Advertising, ed. David Tuerck, Washington, DC: American Enterprise Institute, 161-191.

Russo, J. Edward (1977), "The Value of Unit Price Information," Journal of Marketing Research, 14 (May), 193-201.

Slovic, Paul and Douglas MacPhillamy (1974), "Dimensional Commensurability and Cue Utilization in Comparative Measurement," Organizational Behavior and Human Performance, 11 (April), 172-194.

Weitzman, Martin (1979), "Optimal Search for the Best Alternative," Econometrica, 47 (May), 641-654.

West, Patricia, Dan Ariely, Steve Bellman, Eric Bradlow, Joel Huber, Eric Johnson, Barbara Kahn, John Little, and David Schkade (1999), "Agents to the Rescue?" Marketing Letters, 10 (August), 285-300. 